\title{
A Imersão Altera os Parâmetros Ventilatórios de Indivíduos com Distrofia Muscular de Duchenne?
}

\section{Alba Barros Souza Fernandes}

Fisioterapeuta, Doutora em Ciências, Professora Adjunta do Curso de Graduação em Fisioterapia do Centro Universitário Serra dos órgãos (UNIFESO), Teresópolis-RJ, Brasil.

As distrofias musculares são as doenças neuromusculares mais frequentemente encontradas, sendo caracterizadas por alterações genéticas que levam à deterioração progressiva da força muscular. A Distrofia Muscular de Duchenne (DMD) é a forma mais comum de distrofia muscular com ocorrência na infância, comprometendo 1:3.500 homens nascidos vivos. O diagnóstico é feito na idade pré-escolar, e a deterioração progressiva da força muscular leva à perda da deambulação e à falência respiratória. A perda progressiva da força dos músculos inspiratórios leva a um distúrbio ventilatório restritivo, evoluindo para hipoxemia e hipercapnia noturna. Além disso, a perda da força muscular expiratória resulta em tosse espontânea ineficiente e acúmulo de secreçôes ${ }^{1}$.

Apesar de ser uma doença incurável, é necessário que o tratamento desses pacientes seja multidisciplinar. Dentre os tratamentos utilizados, a fisioterapia apresenta importância fundamental para a prevenção de complicações respiratórias e de contraturas, para a manutenção da força muscular e da mobilidade, visando à promoção de independência para as atividades de vida diárias e, consequentemente, para a melhoria da qualidade de vida. No entanto, é importante que o tratamento não fadigue o paciente, visto que o excesso de exigência muscular acelera o processo degenerativo.

A hidroterapia é comumente indicada para pacientes com DMD. Ao se inserir no meio aquático, o organismo é submetido a diferentes forças físicas, o que gera uma série de adaptaçôes fisiológicas. As forças físicas da água atuam sobre o organismo imerso, provocando alteraçóes fisiológicas extensas que afetam quase todos os sistemas. Dessa forma, o conhecimento e a compreensão das propriedades físicas da água e suas repercussóes na função respiratória são de extrema importância para estabelecer um plano terapêutico.

Neste número da Revista Neurociências, no artigo "Efeitos da Imersão nos Parâmetros Ventilatórios de Indivíduos com Distrofia Muscular de Duchenne"2, os autores se propuseram a analisar os efeitos da imersão em água, no nível da sétima vértebra cervical, nos parâmetros ventilatórios de pacientes náo-deambuladores com DMD, correlacionando estes resultados com os de indivíduos deambuladores de mesma faixa etária e sem doença neurológica.

Considerando critérios de inclusão e exclusão, a amostra do estudo foi composta por 21 indivíduos, sendo o grupo estudo (DMD) formado por oito indivíduos não-deambuladores com DMD e o grupo controle (GC) formado por 13 indivíduos deambuladores saudáveis.

$\mathrm{Na}$ avaliação respiratória, foram mensurados Saturação de Oxigênio, Frequência Cardíaca, Volume Minuto, Frequência Respiratória, Volume Corrente, Pico de Fluxo de Tosse (PFT), Capacidade Vital Forçada (CVF), Pressóes Inspiratória e Expiratória Máximas. A avaliação foi realizada primeiramente em solo, e, após quatro horas de descanso, foi realizada no meio líquido, com os indivíduos sentados em tablado com nível de imersão de C7. Depois de posicionados, os indivíduos ficaram 15 minutos em imersão e foram avaliados.

Os resultados do estudo mostraram que os indivíduos do grupo DMD tiveram uma redução da CVF no meio líquido, em função das forças hidrostáticas que estão agindo em oposição à musculatura inspiratória e ao aumento do volume sanguíneo intratorácico, levando a uma diminuição da complacência pulmonar. A partir das correlações positivas encontradas com a CVF e o PFT, 
quando comparados em solo e no meio líquido, os autores sugeriram uma fórmula para estimar estes parâmetros ventilatórios em meio líquido a partir dos resultados obtidos em solo. Com esses resultados, é possível avaliar mais seguramente a indicação da hidroterapia para indivíduos com DMD, levando em consideração os valores de CVF e PFT estimados em imersão ${ }^{3,4}$.

A literatura é controversa em relação ao comportamento do volume corrente no meio aquático. As alteraçóes na função respiratória são desencadeadas pela ação da pressão hidrostática, que contrabalança a força dos músculos inspiratórios e deforma a parede torácica quando os músculos estâo relaxados. Além disso, a pressão hidrostática promove um deslocamento sangüíneo para o tórax devido ao efeito compressivo da água nos vasos periféricos, aumentando as pressōes intratorácica e transmural nos grandes vasos, e acarretando aumento do trabalho respiratório em $65 \% 5$.

Os autores observaram que a CVF reduziu no meio aquático. Isso pode ser explicado pelo fato de que o aumento do volume sanguíneo no tórax, evidenciado pelo aumento do volume sangüíneo capilar, desloca ar dos pulmóes, diminuindo a capacidade vital, pois o deslocamento sanguíneo congestiona os vasos pulmonares, provocando diminuição na complacência pulmonar. Durante a imersão, em respiração normal, algumas vias aéreas são fechadas, o que acarreta desenvolvimento de áreas de baixa ventilação-perfusão e hipoxemia arterial ${ }^{6}$.
Essas informações são importantes para que o fisioterapeuta possa se embasar ao propor a hidroterapia para pacientes com doenças neuromusculares. Levandose em conta que a fraqueza muscular e a dificuldade de eliminar secreções são os principais fatores responsáveis pelo número de complicações respiratórias que levam ao óbito, é importante saber a redução dos volumes e fluxos pulmonares antes de submeter o paciente à hidroterapia, evitando aumento da dispnéia e fadiga durante o tratamento.

\section{REFERÊNCIAS}

1.Brito MF, Moreira GA, Pradella-Hallinan M, Tufik S. Empilhamento de ar e compressão torácica aumentam o pico de fluxo da tosse em pacientes com distrofia muscular de Duchenne. J Bras Pneumol 2009;35:973-9. http://dx.doi.org/10.1590/S1806-37132009001000005

2.Nicolini RDA, Braga D, Pires CVG, Oliveira RAF. Efeitos da Imersão nos Parâmetros Ventilatórios de Indivíduos com Distrofia Muscular de Duchenne. Rev Neurocienc 2012;20:34-41.

3.Frezza RM, Siva, SRN, Fagundes SL. Atualização do tratamento fisioterapêutico das distrofias musculares de duchenne e de Becker. RBPS. 2008;18:41-9.

4.Sales I, Clebis NK, Stabille SR. Efeitos de exercícios físicos em piscina sobre a função pulmonar do portador de distrofia muscular de duchenne. Um relato de caso. Arq Ciênc Saúde 2004;8:67-72.

5.Fachardo GA, Carvalho SCP, Vitorino DFM. Tratamento hidroterápico na Distrofia Muscular de Duchenne: Relato de um caso. Rev Neurocienc 2004;12:217-21.

6.Sá NC, Banzato TC, Sasseron AB, Ferracini LC, Fregadolli P, Figueiredo LC. Análise comparativa da função respiratória de indivíduos hígidos em solo e na água. Fisioter Pesq 2010;17:337-41. 